\title{
Study on the Context of Advertising Language
}

\author{
Kaiyan Wan ${ }^{1}$ \\ ${ }^{1}$ School of International Education, Capital University of Economics and Business, Beijing, 100026
}

KEYWORDS: Advertising Language; Contextual; Language Function

\begin{abstract}
Context Since first proposed in 1923 by the famous anthropologist Malinowski has become a lot of research in the field of a very important and indispensable concept. Context The importance lies in the close relationship between it and the meaning of the works, the expression was to convey the meaning and expression of ideas is a combination of context by those who have completed condition; and ideas and expression meaning the recipient felt by those who are the recipient to accept the certainty created by the context. Therefore, we can say, the significance of communication activities is a contextual meaning, leaving the specific context will not be able to complete an accurate understanding of the meaning of communication. So, what is the context? It constitutes what factors?
\end{abstract}

\section{Introduction}

Comprehensive study abroad, context can be summarized as follows: Context is divided into broad and narrow context of the points. That Context narrow context, refers to a language locale fragment between language, with its preamble above, below, after the constitution, namely the speech flow context; in addition to the broad context, further comprising a language works writing this article is to study the narrow context of advertising language.

Advertising language, also is known as slogan, referring to the language in the ad text. Since ancient street "selling", graphic media, electronic media in the languages fall into this category. The contextual advertising language refers to the business through advertising, using various media, pragmatic language advertising communication activities are involved in a variety of contextual factors. These factors include background images, images, sound, color, music, and other contexts and they are closely related to the context of the ad language. Wherein the screen is the main language in the context of advertising has an irreplaceable role in advertising, advertising language of expression plays an important supporting role.

As a special verbal communication activities, the role of advertising in the audience auditory and visual systems and simultaneously deliver dynamic or static form of information, therefore, from the point of view of the composition of advertising, visual communication and image part depend on the screen, hearing Transfer Part it relies on language. Both of them are the main components of the advertising system, each with advantages and disadvantages, mutual penetration, complement each other, and other parts of the sound, music, etc. together to complete the transfer and expression of the theme of the ad. In this article, the author of the picture features the slogan of, for example, describes the important role of context in the ad phrase. 


\section{Contextual Advertising can Play a Role in Language Interpretation}

Ad language in advertising, advertising in general reveal the nature of the product, functions, features and other in-depth information, indirect expression, abstract meaning of freedom, such as durable, long-term, higher calcium content. The screen is capable of expressing a specific, direct, fixed meaning, and therefore easier for the audience to understand. For example, backgammon music phone ads appear at the beginning of the first picture is the South Korean star holding a cell phone, with a headset comfortably lounging on the beautiful streets of France, this screen will guide your audience immediately think this ad is mobile advertising It can help you faster and better understood, accepted language advertising information transmission.

In addition, the screen can supplement the specific meaning of language is not expressed, to make it clearer content, rich, increase the allure of the product. For example, "Trimeresurus wine" slogan: "melting ancient masters, set herbal essence (Subtitle: ice taste more special) Millennium heritage, Trimeresurus wine." The advertisement did not have much appeal, but a narrative. However, combined with the picture, we see the wine workshop in the mountains between the years, dozens of workers on the rear naked back down from the mountain spring water, poured into vats to do taken from pure natural green bamboo leaves wine fermentation, we understand the "ancient masters" and "herbal essence" of the specific meaning, to understand Trimeresurus wine raw materials from natural and more healthy. Therefore, the more strongly felt the charm of the wine and to better understand the intent of the advertiser.

Moreover, pictures and other context can determine the specific meaning of the language. For example, jumping language TV advertising is relatively strong, simple grammar, between words, the lack of contact between the sentence and the sentence, so if there is no picture context as an effective complement to know we can not determine the exact meaning of the language. Such as "ice moving summer, do not play not cool", which is "Harbin Beer" TV ad words. Looked at in isolation from the context of this sentence, it can not pass any product information, because without generating this context the word, we can not know those described in the summer, play, play it cool with what commodity-related sentences . But (group of young people drinking beer in the hot, summer comfortably racing, dancing) in a particular screen, its significance is easier to understand: It was with Harbin Brewery, the summer will become icy, we will have more fun. Harbin Brewery can bring us happy and interesting life. Again, the new Tide of the ad: "I use the wall Li Jie introduced (New Tide), clothes washed it clean, and yesterday he took half a day in the mirror, that will not go away, especially smug." "He" is the Who? Needless language titles, because the screen is not already clear to us that father nor the mother re love smug son. If there is no picture, more than one meaning it will not show up, the expression of the effect will be greatly reduced.

\section{Contextual has A Rich Context, Complementary Semantic Function}

In the ad, contextual advertising is an important means of auxiliary language meaning, with the help of context, the semantic information advertising language richer.

Advertising language sometimes because there are strong jumping, less related words and other characteristics, and therefore need to make up some of the context omitted semantic content. For example, "Diaopai toothpaste" in TV commercials only five sentences: (1) (2) I have a new mother she seemed not so annoying (3) She laughs like my mother (4) truth pay, spiritual crossroads (5) Diaopai toothpaste this five-sentence paragraph and the second sentence seems to be able to put together, but "it seems not so annoying," tell us what the story seems to be the middle of the second 
and third sentences seem to have an emotional sublimation, never how to start like hate. Such emotional experiences but do not know what kind of event was raising it to such a degree. The fourth sentence is highlighted theme, the absence of context, it seems a bit baffling. The truth how to pay? Mind how the intersection?

In short, in the ad, the lack of context and only themed ad language is not complete. This requires context to supplement interpretation. Ads with pictures before and after that we can fully understand the theme of the ad:

\begin{tabular}{|l|l|}
\hline \multicolumn{1}{|c|}{ Picture } & \multicolumn{1}{|c|}{ Language } \\
\hline $\begin{array}{l}\text { (1) little girl by the door, looking aggrieved } \\
\text { young couple out the door smiling }\end{array}$ & (1) I have a new mother \\
\hline $\begin{array}{l}\text { (2) a test for the new mother smiling little girl } \\
\text { knitted sweater, unhappy little girl }\end{array}$ & She seemed not so annoying ah \\
\hline (3) little girl staring blankly rain & (3) She laughs like my mother \\
\hline $\begin{array}{l}\text { (4) new mother Mianhanweixiao of } \\
\text { Chengzhaoyusan take the little girl home }\end{array}$ & (4) truth pay, spiritual crossroads \\
\hline $\begin{array}{l}\text { (5) morning, the little girl came to the room, } \\
\text { rubbing his eyes and face, has gracefully } \\
\text { toiletries and toothpaste greets Diaopai }\end{array}$ & (5) Diaopai toothpaste \\
\hline $\begin{array}{l}\text { (6) little girl turned and smiled phase, as a new } \\
\text { mother }\end{array}$ & \\
\hline $\begin{array}{l}\text { (7) appear subtitle "white" and the product } \\
\text { image. }\end{array}$ & \\
\hline
\end{tabular}

Advertisements are often short refining, and sometimes loss of a single table in terms of meaning, abstraction, and that has a specific context, polyline features, so when semantic can compensate for this shortcoming, so that semantic advertising richer, even with humor to the audience, laugh of joy and happiness. For example, the beginning of a unified old altar pickled beef noodles ad that has many Wang Han's face picture, the second picture appears Wang Han, walked, said: "Some people imitate my face, someone to imitate my face." We suddenly realized, the first screen of many of Wang Han is a fake, and the second screen wanghan is true. This is the authentic face of the publicity his endorsement of indirect attack "counterfeit Mask" Like many false Wang Han, like, should be resolved and trade-offs in life. Another example is the "we break up, you're too boring, needs a new sense of life." Thought it may sound to break up the Declaration, but a look at the picture, is a man in the face of a bowl of instant noodles to say, the use of language pun way binding on the screen accurately interpret the meaning and supplements can not help but laugh.

\section{Context can Inspire Justice, Given Language, Advertising Themes Feeling of Beauty}

A screen with a semantic rich, delicate features, and therefore, some of the screen can be more detailed rendering the atmosphere, the expression of language clearly explained the meaning, in particular the advertiser passed to the audience between the lines, such as the advertiser's corporate culture, some additional philosophical the meaning of life or some understanding. For example: "I stopped, when the United States that time, the United States that mask, to stop and enjoy the beauty." Listen to this single advertising slogan, we know this is the mask of advertising, but "stop and enjoy the beauty," Why come? Combined with the picture, we can see the city's white-collar hard working day stepping on wood played out in a beautiful natural landscape, putting on a mask 
encrusted with flowers lying in hammocks dangling, a laid-back clean sight! Plus a wonderful soul music so that the audience can follow, quiet and relaxed. In this ad, the advertiser wants to tell us not only to bring a face mask repair, can also bring spiritual rest and nourishment. Which busy girl can refuse the temptation and call it?

Another example is the classic "Southern black sesame paste," the ad, deep granite alleys, quaint village houses, gray-haired old man's childhood memories gluttonous image, constitute a group of beautiful and moving TV picture, adding in South mood cries uncle and memories of past voiceover, sound and pictures together to convey a warm and mellow motherly compassion, advertising slogan, "an aroma, a ray of warmth" of "warm" and therefore had a rich sense of association distributing warm sense of truth, sesame paste brings warmth between people, the manufacturers of customer care, human, product name, manufacturer Cohesion in the minds of people in nature, are closely linked, meaning distant.

In summary, in the context of advertising can sense language interpretation, understanding, and play an important role on the rich language environment rendering is an effective supplement and deepen advertising. Therefore, we should collaborate together with advertising language, correctly and effectively communicate advertising theme will. Zuo Feng, as the teacher said, "the image of reality mainly in five areas: direct, specific, comprehensive, multi-meaning, at present, while the symbolic language of performance associated with five areas: indirect, abstract, analysis, univocal, freedom "that is to say, the picture generally presented to you is the surface, the appearance of the information content of the image, concrete reality; and the language passed to you is more indirect and difficult to be observed abstractions. Thus, the two features together with advertising and media feature determines the language of the picture must be close coordination and cooperation with each other, dissolve each other, explain the picture, description and elaborate language, lyrical mutual adaptation, to create a harmonious unity, obedience advertising theme and needs. Both are indispensable.

The role of advertising is to attract audience language and to give them the desire to purchase products and persuasion by stimulating way. From the analysis of the language and to narrow advertising picture point of view represented context, the semantic advertising only in the specific context of the screen or the like in order to get a better explanation and elucidation, advertising screen and some other languages only in TV ad under forth can be more complete and more accurate expression of the theme of the ad, complete the production of the purpose of advertising. Therefore, pictures and other context and language are inextricably linked, both with each other not only shine but also mutual tolerance, we express a theme with the slogan, it is necessary to show the context, we study advertising language, also must study the slogan the role of the environment.

\section{Acknowledgements}

Project: This research was Beijing Social Science Fund Project "Characteristics and Innovation of Chinese advertising Language based on an International Perspective"

Project NO. 14WYC059

\section{REFERENCE:}

[1] Main editor Ding Gengyuan, "Introduction to advertising language" [A], Beijing: China Radio and Television Press, 2007.

[2] Beijing Broadcasting Institute Television Department of the Academic Committee of the 
Chinese Council of Applied Science Editor TV edited "Chinese Science Applications TV" [A], Beijing: Beijing Normal University Press, 1993.

[3] Liu Yanchun: "Television advertising language type and creation" [A], Beijing: China Economic Publishing House, 2004.

[4] Li Zuofeng: "TV Special picture and sound structure of language" [A], Beijing: Beijing Broadcasting Institute, 1999.

[5] Zhang Hao Da, Xiao Yanze: "Concise Advertising Tutorial" [A], Beijing: Peking University Press, 2004.

[6] Huang Borong, Liao Xudong: "Modern Chinese" [A], Beijing: Higher Education Press, 1997

[7] Ma Xuesong: "From the point of view of English Rhetoric ad in the" Sound "function" [J], "Economic Research Guide" 201123.

[8] Huang Qunying: "Television advertising language charm" [J], "Southwest University of Science and Technology" (Philosophy and Social Sciences) 2003 fourth period.

[9] Zhang Lanying: "Television advertising language Exploration" [J], "Xingtai Teachers College" (Comprehensive Edition) 19961.

[10] Chen Shuping: "Language of TV advertising context" [J], Huainan Normal College, 20046. 